\title{
Coloniality and Mental Health, Neurological and Substance Abuse (MNS) Disorders in Guyana's Prisons Today ${ }^{1}$
}

\author{
Queenela Cameron $^{2}$ and Dylan Kerrigan ${ }^{3}$
}

\begin{abstract}
There is a relationship between the social actions and social structures laid down during colonialism, and the social hierarchies and inequalities that developed as British Guiana moved slowly from British colony to Independent Guyana. From slavery and indigenous marginalisation, to indentureship and colonial social relations, modern Guyana emerges from the legacies of an Imperial project, and most notably "enslavement, immigration, and population management" (Anderson 2019). In the context of Guyana's prisons today, the echoes and ghosts of this Imperial project can be said to still haunt the grounds and insides of these decaying buildings, as well as stalking the lives and minds of inmates themselves.
\end{abstract}

Keywords: Prisons, Coloniality, Mental Health, Guyana

\section{Introduction}

In this paper we undertake thematic analysis of 20 semi-structured interviews conducted with inmates at both Georgetown and Lusignan ${ }^{4}$ prisons in 2019 and note how coloniality and the afterlife of slavery (Mignolo 2007), with its continued consequences for mental and physical health, manifest and are a central aspect shaping everyday life within these two Caribbean prisons today.

\section{Methods and Sample}

Each of our semi-structured interviews lasted between 60 to 90 minutes and was conducted in the chapel of the prisons by us working together. One of us is Guyanese, while the other is a Trinidadian-British. This local Caribbean heritage helped in terms of code switching to Creole with inmates and understanding the relevant local socio-cultural context. We spoke to ten prisoners clinically assessed with MNS disorders and ten not diagnosed with MNS. Based on these criteria the Guyana Prison Service chose the individual prisoners for us to interview. The questions for these interviews were developed from a much larger quantitative sample done across all five of the Prisons in Guyana by the Inter-American Development Bank and Government of Guyana in 2017 (Sarsfield and Berman, 2017). This allowed us to decide what line of questions we wanted

\footnotetext{
${ }^{1}$ This paper is based on research conducted for the ESRC-funded project Mental Health, Neurological and Substance Abuse (MNS) Disorders in Guyana's Jails: 1825 to the present day (award no. ES/S000569/1). This project is a collaboration between the University of Guyana and the University of Leicester, in partnership with the Guyana Prison Service. The project brings into dialogue researchers in History, Criminology, Sociology and Literature. It takes both a multi-disciplinary and interdisciplinary approach to key questions about the form, function, and experience of incarceration, encompassing inmates and the people who work with them. It encompasses both the British colonial period, and the era since Guyana's independence in 1966.

${ }^{2}$ Lecturer, Department of Government and International Affairs, University of Guyana, Guyana. Email: queenela.cameron@uog.edu.gy.

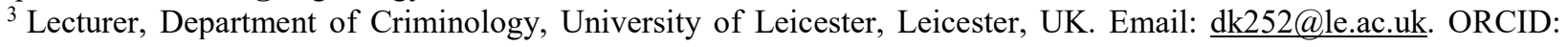
0000-0003-2453-9804

${ }^{4}$ During the development of this paper on $12^{\text {th }}$ July 2020 , Lusignan prison was mostly burned to the ground.
} 
to pursue. In the main we followed a semi-structured interview protocol design to capture a limited life history from each participant. We followed the ethical directions agreed with our review panel and provided consent forms and information sheets to all participants, which were explained to all prisoners in front of the prison welfare officer. Our interviews were transcribed then manually open-coded for sub and major themes. A second process of coding is ongoing currently via the software NVivo.

\section{Analysis: General medical profile}

Of the ten prisoners who had been clinically assessed for mental health issues, both the Guyana Prison Service welfare officers and the inmates themselves told us that the main manifestations were psychosis, schizophrenia, multiple personality disorder, paranoid schizophrenia, hearing voices, hallucinations, anxiety, depression, stress, and compulsive lying. One inmate also noted he had been diagnosed but had not been told what his condition is. In terms of neurological disorders, one person we interviewed told us they had been diagnosed for epilepsy.

All of those ten persons with clinical diagnoses were on medication, from injections to daily tablet regimens. Many complained about the side effects of injections noting that they caused them to sleep a lot, drool and feel paralysed. Some of those on tablets remarked on their effectiveness in treating their conditions. Some said they had found the right tablet for their condition. Many suggested they needed to keep taking the tablets and would do so on release. Some spoke of visions at night; of seeing people who weren't there and of hearing keys in the door and when they looked no one actually being there. Two inmates, one who had been convicted of sexual offences, told us of being sexually molested by ghosts in their sleep.

Those diagnosed with MNS in Georgetown prison described other inmates in the "Chalet" - the space where those with clinical assessments are held - banging their heads against the wall, screaming and having spontaneous outbursts, and making animal sounds. Even though they were under treatment and discussed this with us, eight of the ten persons who were in, or had previously been in, the Chalet denied to us they had any clinical mental health issues. Apart from two inmates with MNS disorders, the other eight told us they had no mental health diagnoses or any other physical health problems before their imprisonment. One inmate said their mother had mental health issues, adding that maybe it was hereditary as her other son had MNS disorders too.

In terms of substance-use in prison, of the 20 persons we spoke to all either currently smoked cannabis, had previously smoked cannabis before prison, or if they were not cannabis smokers did not have a problem with others smoking cannabis. Some suggested it helped them. Others suggested it caused issues like fights or made some inmates more depressed. The price of cannabis in prison we were told is prohibitive for most. However, we were also told that some inmates smoke together and share it. In general, prisoners informed us that it is prison orderlies who pass the cannabis throughout the prisons. Also, prison guards told us they generally turn a blind eye to it as cannabis smoking makes prisoners less aggressive overall and this makes their own job more bearable. The amount consumed seemed low, with inmates who smoked suggesting one joint every couple of days. There was less alcohol use in comparative terms, but homemade fruit wine is still consumed monthly, based on the difficulties in keeping the homebrew hidden from guards during its preparation. Two persons told us they had been cocaine users (smoking rather than snorting) prior to entry to jail. 
In terms of support from welfare officers and the psychiatric staff from Georgetown General Public Hospital, aside from complaints about medication, all the inmates we spoke to described the welfare and psychiatric staff as good people who looked after them. The welfare officers themselves had a slightly different perspective. They told us they had to deal with hundreds of inmates and could not cope with the large numbers who constantly required their attention.

\section{Socio-cultural and economic profile}

The narrative data we collected suggested that all those we spoke to (both with or without MNS disorders) grew up and had home lives in the economically depressed and socially challenged neighbourhoods of Guyana. The majority came from historically poor areas of Georgetown, such as West and East Ruimveldt, Albouystown, and Laing Avenue. There were also persons from noneconomically depressed communities, but ones that are still economically challenged. They include Lethem, Essequibo, South Ruimveldt, Kitty, and Berbice.

Socio-economic challenges included being orphaned or running away from home; absent fathers and growing up with one parent, some with multiple partners; having to move homes multiple times; and often not living with parents and siblings, and instead with aunties or grandparents. In terms of their mother's role in the family we heard stories of single mothers struggling to raise a family, and stereotypical and biblical ideas about gender roles such as men having ownership of women. Many had not been residing with their families or children prior to detention. Two respondents told us they had been homeless since they were fourteen and fifteen years old. Another told us he had been homeless since he was nine (Lee et al. 2000). There were also many stories that growing up was fun but got harder during teenage years

Nearly all of the inmates we spoke to did not finish secondary school. The context for this was they needed to assist their families financially, so they left school well before they were sixteen. This meant most had no Caribbean Examination Council passes (CXCs are Caribbean GCSE qualifications). This confirms the 2017 Guyana inmate study, which estimated that $80 \%$ of inmates did not finish secondary school (Sarsfield and Bergman 2017). In terms of the troubles and social problems that impacted them and their families growing up, many described a lack of social and life skills including literacy, poor parental guidance, violence in the home, and low paying jobs. Also, friends and peers rather than elders became role models. Two inmates also told us about being homeless and how street life was a negative experience which lines up with previous research in Guyana (Thomas-Holder 2007). These various social problems have a relationship to personal psychological health and well-being, and in sociological terms can lead to many making choices to get involved in crime. The main pre-imprisonment stress factors we identified from the interviews were lack of employment and poverty. The jobs they had done were in the main low income, long hours, working class jobs such as drivers, masons, construction, minibus conductors, farmers, taxi drivers, and peddlers.

In the context of psychological damage, such socio-economic profiles suggest a relationship between social problems and life skill deficits (Antonowicz and Ross 2005). Or, put in sociological terms, based on their social location both geographically and in terms of socioeconomic situation and social class, social problems in at-risk communities have caused psychosocial injuries and life skill deficits around decision making, reasoning, anger management, 
literacy and more, for many of these men. This can force or lead some to develop means to achieve everyday goals, including violent crime and hustling on the street.

\section{Patterns and characteristics of life in prison}

In terms of crimes committed, most told us a story of their crime being less severe, or less problematic, than we saw in their charge sheets and court documents. The majority of our small sample of 20 were incarcerated or on remand for murder/manslaughter (12). At the same time there were also sexual offenders (grooming), as well as persons serving sentences for drug trafficking, assault, and domestic violence.

In terms of coping without family and community now they were in prison, all but one of those we spoke to suggested that this caused personal difficulties. The one person who did not say this had been homeless since the age of nine years old. Some of those we spoke to did get family visits; but these were not frequent and happened at most once a month.

All those we spoke to used religion to make sense of and cope with their situation. Most practiced evangelical Christianity (Islam was present in Lusignan, but not amongst our interview sample. And one of the persons we spoke to at Georgetown did identify as Muslim; the other 19 identified as Christian). In terms of a daily routine many spoke of being depressed and spending a lot of time sleeping. Since the 2017 fire that destroyed much of Georgetown Prison's infrastructure, Lusignan became a different prison to Georgetown in that inmates go outside to the yard more regularly and in Georgetown they no longer could. There are a few space-constrained cricket matches, but not often. At both prisons the inmates said they watched one communal TV (often with no sound); some read newspapers, some played dominos; and some complained about the quality and quantity of the food. At Lusignan, some prisoners on good behaviour got the opportunity to do carpentry, some do tailoring, some work in the stores, some work in the kitchen, and orderlies - who we were told pass contraband through the prison - seemed to have decent amount of freedom to move throughout the prison.

In terms of stress in prison, the men spoke of loneliness, missing their family, not being able to contact them via mail or phone calls, not having information about their case i.e. their day of release, their deposition, their court dates. Boredom was a factor they all mentioned. This was hardest on arrival but became more accepted as they became used to it over time and adapted. Violence happens but most told us they had quickly learned to avoid it. Overcrowding was a definite stressor, especially where inmates were sharing a single mattress, which could lead to fights during the night. Bathing and toilet facilities were a big stress not least for their parlous state and the absence of privacy. Sleeping close to toilets was described to us as a big negative. Also, most of the men had learnt some basic rules like keeping to yourself and not trusting others. Some smoked cigarettes, and all prayed as ways to fill the boredom.

\section{Discussion}

In this section we now discuss three themes we developed textually from the interview transcripts.

\section{Broken Family}

The data suggests on first glance that "broken families" are a common connector across those men we spoke to in prison. This is of course a simplification. More accurately - non-nuclear families 
hide a larger trans-historical, racialised socio-economic context. The stereotypical western nuclear family, and a lack of it during colonialism and today as a cause of why some men make a choice to be involved in crime (Barrow 1996), is an umbrella term that erases the historical socioeconomic inequalities and hierarchies of local society as a connection and bridge to social problems first created historically during Empire. Here, social problems played out in racialised ways and led to adaptation and responses in culture and family structures. The non-nuclear family today in the Caribbean and in the past is a reflection of the coloniality of power rather than a root cause of criminality. In transhistorical terms "broken family" can be read as code for long-standing socio-economic inequalities and hierarchies, or "structural violence", and how they impact the socio-economic and socio-cultural profile of most of the men we spoke to (Trotz 2003). As the anthropologist Maarit Forde has noted of Trinidad, "The causality between 'broken families' and social problems imagined in this discourse allows neoliberal policymakers to treat social suffering as resulting from the immorality of the lower class instead of addressing the deep socioeconomic disadvantages and inequality entrenched in the region" $(2018,51)$.

\section{Religion}

All twenty inmates we spoke to and all the prison officers we interacted with read the Bible and practiced evangelical Christianity. Punishment for many in Guyana, today as in the past, is understood through a lens of religion and Christian morality (Clarke 2010). Religion in the Caribbean is a powerful legacy from colonialism to the present (Khan 2003, 768), and is found in prisoner and prison staff cosmologies on discipline and punishment (Henry 1999). As many persons who end up in prison or who staff the prisons come from poor social class backgrounds there seemed to be a relationship between childhood experiences of evangelical Christianity and coping with experiences of being in prison (Clarke 2010,111). It was almost as if the stress of prison (and the reality of their crime of murder or sexual offence) caused a traumatic response and turn back to childhood cultural memory to make sense of events. Similarly, the staff we spoke to that questioned the dehumanising prison infrastructure and processes, or experienced mental health problems connected to their jobs, seemed to find that their evangelical Christian beliefs around punishment justified the work. In this sense, religious explanation becomes a way to face up to or understand and makes sense of what is the transhistorical and dehumanising sociological context of the prison both for inmates and staff.

\section{Culture}

Due to a lack of funds and infrastructure, prisons in the Caribbean, as they were in colonial times, are also used to house those with mental disorders (Anderson, Moss and Adams 2020), and those who have often dropped through the limited social safety nets provided by cash strapped Caribbean governments (Smith 2014; Moss and Adams 2020). This was the same in the past, when colonial administrators ignored the relationship between colonialism, labour systems and mental health in understanding why some people were violent or engaged in public disorder; or that the physical and mental health of the colonised under the violence, social destruction and dislocation of colonialism was damaged (Hickling 2002, 114; C. Mills and Hilberg 2018). Today, recognition that intergenerational trauma and relative poverty have a relationship to mental health and who ends up in jail is still missing in the administration of prisons. Authorities then and now have often disconnected the relationship between social problems and an individual's experience of them, and the consequent psychological impacts this produces. For example, research shows prisoners both 
in the Caribbean and around the world have higher rates of mental ill health, substance use disorders, self-harm and suicide than people in the general population (Prison Reform Trust 2016).

On a cultural level many inmates with mental health disorders in these two Caribbean prisons, like in others, are in denial of their mental health condition because of the historical stigma attached to 'craziness' in the Caribbean (Arora \& Persaud 2019, 4-5). As it was during colonial times, these symptoms are often explained away by having a "spiritual" or supernatural problem (Hickling 2002). One hears voices, because one has a gift. Intervention from evangelical Christianity such as praying out evil spirits or seeking the assistance of a medicine man still predominates over seeking professional mental health treatments (Arora \& Persaud 2019). The culture of privacy in the Caribbean, involving keeping things to oneself and not causing talk and gossip, also means inmates are reluctant to speak to medical professionals about mental health. Like in the past, persons with mental health problems are often found in jail and not in professional care facilities, which are few in number across the region.

\section{Conclusion}

The inherent social class inequalities established by the capitalist mode of production and the social systems it created during its emergence from colonialism and imperialism can be hidden today by myths of individual failure, broken families and religious destiny (Forde 2018). Prisons and prisoners are not the top of the list of concerns for politicians or the voting public. Yet as many scholars have pointed out, prisons are a reflection of a society's values (Silvia 2003). Current Caribbean values are cultural responses to the social realities and economic environments of Caribbean history. This of course includes slavery, colonialism, capitalist exploitation and underdevelopment, and how these political and economic eras shaped ideas about social hierarchies, punishment and morality. For the public and politicians, prisons play an important social ritual. Prisons provide confirmation for what many people in the Caribbean have been brought up and socialised to believe; that punishment - like parental beating ("licks") from our parents' time or even the cane from colonial days - corrects individual social behaviour (Hodge 1974). Yet social workers and sociologists suggest emotional responses centred on fixing individuals through punishment cannot fix social problems. Nonetheless, punishment is the focus of long-standing criminal justice systems found in the Caribbean and handed down as independent nations in the post-colonial era.

Coloniality in this sense shapes the post-colonial present, and in the context of this initial prison interview data we can say it does it in various ways. These include cultural systems - such as placing responsibilities for criminality on the idea of broken families and the stigmatisation in local culture around mental illness; systems of knowledge - such as morality around punishment being based on Christian religion; and systems of hierarchies - such as social class that see those from poor socio-economic background dominating who ends up in prison.

\section{References}

Anderson, Clare. 2018. A Global History of Convicts and Penal Colonies. Bloomsbury Publishing. 
—. 2019. “An Historical Perspective on Guyana’s Jails.” MNS Disorders in Guyana's Jails 1825 to the Present Day. 2019. https://mnsguyana.le.ac.uk/2019/09/30/an-historical-perspectiveon-guyanas-jails/.

Anderson, Clare, Mellissa Ifill, Estherine Adams, Kellie Moss. 2020. 'Guyana's Prisons: Colonial Histories of Post-Colonial Challenges', The Howard Journal, Vol 59 No 3. September 2020, ISSN 2059-1098.

Anderson, Clare, Kellie Moss and Estherine Adams. 2020. Insanity and Imprisonment in colonial British Guiana. LIAS Working Paper 2020/4. Leicester: Institute for Advanced Studies.

Antonowicz, D.H. and Ross, R.R., 2005. Social problem-solving deficits in offenders. Social problem-solving and offending: Evidence, evaluation and evolution, pp.91-102.

Arora, Prerna G., and Sarika Persaud. "Suicide among Guyanese youth: Barriers to mental health help-seeking and recommendations for suicide prevention." International Journal of School \& Educational Psychology (2019): 1-13.

Barrow, C. 1996. Family in the Caribbean. Kingston, Jamaica: Ian Randle Publishers Ltd.

Clarke, K.M., 2010. The Politics of Faith and the Limits of Scientific Reason: Tracking the Anthropology of Human Rights and Religion. Religion and Society, 1(1), pp.110-130.

Hickling, Frederick W. 2002. "The Political Misuse of Psychiatry: An African-Caribbean Perspective." The Journal of the American Academy of Psychiatry and the Law 30 (1): 112-19.

Hodge, M. (1974). The shadow of the whip: A comment on male-female relations in the Caribbean. In O. Coombs (Ed.) Is Massa day dead? Black moods in the Caribbean.

New York: Anchor Books.

Forde, M., 2018. Respectable Families and the body politic. Suomen Antropologi: Journal of the Finnish Anthropological Society, 43(4), pp.48-54.

Lee, Judith AB, Stella Odie-Ali, and Michael Botsko. 2000. "The invisible visibles: A study of the needs of the homeless and mentally ill in Guyana." International Social Work 43, no. 2 (2000): 163-178.

Henry, Paget. 1999. Wilson Harris and Caribbean Philosophical Anthropology. The CLR James Journal, 7(1), 104-134. Retrieved August 25, 2020, from http://www.jstor.org/stable/26759424

Khan, A., 2003. "Isms and schisms: Interpreting religion in the Americas". Anthropological Quarterly, 76(4), p.761-774.

Linebaugh, Peter. 2003. The London Hanged: Crime and Civil Society in the Eighteenth Century. Verso. 
Mignolo, W.D., 2007. Introduction: Coloniality of power and de-colonial thinking. Cultural studies, 21(2-3), pp.155-167.

Mills, C, and E Hilberg. 2018. “'Built for Expansion': The 'Social Life'of the WHO's Mental Health GAP Intervention Guide." Sociology of Health and Illness.

Prison Reform Trust. 2016. "Bromley Briefings Prison Factfile Autumn 2016." London. http://www.prisonreformtrust.org.uk/Portals/0/Documents/Bromley Briefings/Autumn 2016 Factfile.pdf.

Sarsfield, Rodolfo, and Marcelo Bergman. 2017. "Study of Inmates in Guyana." Buenos Aires: Center for Latin American Studies on Crime and Violence, UNTREF, Inter-American Development Bank.

Silvia, P. J. 2003. Throwing away the key: Measuring prison reform attitudes. Journal of Applied Social Psychology, 33, 2553-2564.

Smith, Leonard. 2014. Insanity, Race and Colonialism: Managing Mental Disorder in the PostEmancipation British Caribbean 1838-1914. London: Palgrave Macmillan.

Thomas-Holder, Barbara. 2007. 'Street Children, of Guyana'. In Homelessness and Street Children in the Caribbean. Edited by Ronald Marshall, Joe Springer and Ralph Premdas, 71- 96. The University of the West Indies School of Continuing Studies, St Augustine Trinidad and Tobago.

Trotz, D. Alyssa 2003. Behind the Banner of Culture? Gender, 'Race,' and the Family in Guyana. New West Indian Guide 77 (1\&2): 5-29. https://doi.org/10.1163/13822373-90002527. 